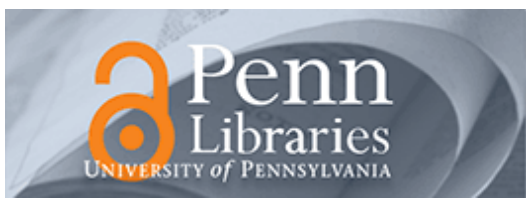

University of Pennsylvania ScholarlyCommons

Wharton Pension Research Council Working

Papers

Wharton Pension Research Council

$10-1-2008$

\title{
How Pension Rules Affect Work and Contribution Patterns: A Behavioral Model of the Chilean Privatized Pension System
}

Petra Todd

School of Arts and Sciences, University of Pennsylvania, ptodd@econ.upenn.edu

Viviana Vélez-Grajales

School of Arts and Sciences, University of Pennsylvania, vivianav@econ.upenn.edu

Follow this and additional works at: https://repository.upenn.edu/prc_papers

Part of the Economics Commons

Todd, Petra and Vélez-Grajales, Viviana, "How Pension Rules Affect Work and Contribution Patterns: A Behavioral Model of the Chilean Privatized Pension System" (2008). Wharton Pension Research Council Working Papers. 255.

https://repository.upenn.edu/prc_papers/255

This paper is posted at ScholarlyCommons. https://repository.upenn.edu/prc_papers/255

For more information, please contact repository@pobox.upenn.edu. 


\title{
How Pension Rules Affect Work and Contribution Patterns: A Behavioral Model of the Chilean Privatized Pension System
}

\begin{abstract}
Chile has been at the forefront of pension reform, having switched in 1980 from a pay-as-you-go system to a fully funded privatized accounts system. The Chilean system served as a model for reform in many other Latin American countries and has also been considered by U.S. policy makers as a possible prototype for social security reform. Some of the criticisms of the Chilean system are low coverage rates and contributions rates among certain segments of the population. In 2006, the Chilean government proposed some reforms aimed at increasing coverage and contribution rates and expanding the safety net provided by the system to poor households. This study evaluates how changes in pension system rules affect working behavior and pension contribution patterns using data from a new Chilean household survey administered in 2002 and 2004 linked with administrative data from the pension regulatory agency. It develops and estimates a dynamic model of decision-making about working in the covered or uncovered sectors of the economy and studies implications for pension accumulations. The estimated model is used to simulate behavior under different pension system rules, such as a change in the number of years of contributions required for the minimum pension or a change in pension plan fees.
\end{abstract}

\section{Disciplines}

Economics 


\title{
How Pension Rules Affect Work and Contribution Patterns: A Behavioral Model of the Chilean Privatized Pension System
}

\author{
Petra Todd and Viviana Vélez-Grajales
}

October 2008

\author{
PRC WP2008-27 \\ Pension Research Council Working Paper \\ Pension Research Council \\ The Wharton School, University of Pennsylvania \\ 3620 Locust Walk, 3000 SH-DH \\ Philadelphia, PA 19104-6302 \\ Tel: 215.898.7620 Fax: 215.573.3418 \\ Email: prc@wharton.upenn.edu \\ http://www.pensionresearchcouncil.org
}

This work was supported by a grant from the Social Security Administration through the Michigan Retirement Research Center (Grant \# 10-P-98362-5-04). The findings and conclusions expressed are solely those of the author and do not represent the views of the Social Security Administration, any agency of the Federal government, or the Michigan Retirement Research Center. We are also grateful to the National Institutes of Health - National Institute on Aging (grant number P30 AG12836); the Boettner Center for Pensions and Retirement Security at the University of Pennsylvania; and the National Institutes of Health - National Institute of Child Health and Development Population Research Infrastructure Program (R24 HD-044964) for funding this research. We thank Olivia Mitchell and Jere Behrman for helpful comments. Opinions and errors are solely those of the authors and not of the institutions with whom the authors are affiliated. (C) 2008 Pension Research Council of the Wharton School of the University of Pennsylvania. All rights reserved. 


\title{
How Pension Rules Affect Work and Contribution Patterns: A Behavioral Model of the Chilean Privatized Pension System
}

\author{
Petra Todd and Viviana Vélez-Grajales
}

\begin{abstract}
$\underline{\text { Abstract }}$
Chile has been at the forefront of pension reform, having switched in 1980 from a pay-as-you-go system to a fully funded privatized accounts system. The Chilean system served as a model for reform in many other Latin American countries and has also been considered by U.S. policy makers as a possible prototype for social security reform. Some of the criticisms of the Chilean system are low coverage rates and contributions rates among certain segments of the population. In 2006, the Chilean government proposed some reforms aimed at increasing coverage and contribution rates and expanding the safety net provided by the system to poor households. This study evaluates how changes in pension system rules affect working behavior and pension contribution patterns using data from a new Chilean household survey administered in 2002 and 2004 linked with administrative data from the pension regulatory agency. It develops and estimates a dynamic model of decision-making about working in the covered or uncovered sectors of the economy and studies implications for pension accumulations. The estimated model is used to simulate behavior under different pension system rules, such as a change in the number of years of contributions required for the minimum pension or a change in pension plan fees.
\end{abstract}

\author{
Petra Todd \\ Professor of Economics \\ Associate of the Population Studies Center \\ University of Pennsylvania \\ 520 McNeil Building, 3718 Locust Walk \\ Philadelphia, PA 19104 \\ ptodd@econ.upenn.edu \\ Viviana Velez-Grajales \\ Department of Economics \\ University of Pennsylvania \\ 160 McNeil Building, 3718 Locust Walk \\ Philadelphia, PA 19104 \\ vivianav@econ.upenn.edu
}




\section{Introduction}

Many pay-as-you-go social security systems in the United States, Europe and some parts of Asia face impending insolvency due to rising numbers of pensioners per worker. Policy-makers are considering a number of potential reforms, one being a transition away from a pay-as-you-go system to a fully funded privatized retirements accounts system. Chile was at the forefront of social security reform when it replaced its pay-as-you-go system with a privatized accounts system in $1980 .^{1}$ The Chilean system has since been a prototype for pension reform in many other Latin American countries, including Mexico, Argentina, Peru, and Uruguay.

Previous research on Chile finds substantial benefits from moving to a private retirement accounts system in terms of developing well-functioning capital markets and stimulating economic growth. However, there continues to be a heated debate about other relative merits of a decentralized, private accounts system vis-à-vis a more centralized system. Critics of the privatized system point to some problematic aspects, such as commissions and fees that some consider to be excessive. The system has also come under criticism because of low coverage rates and low rates of contributions among certain segments of the population.

In Chile, as in many other Latin American countries, there is a dual labor market with both covered and uncovered sector workers. In the covered sector, individuals sign labor market contracts, pay taxes, and, under law, are obliged to contribute $10 \%$ of their paycheck to the privatized pension

\footnotetext{
${ }^{1}$ The adoption of the private accounts system was in part influenced by University of Chicago economists that were advisors to Augusto Pinochet's during his military regime.
} 
accounts system and an additional percentage for health insurance, disability insurance and unemployment insurance. The uncovered sector consists of wage workers with no formal labor contracts and self-employed workers who are not required to contribute to the pension program under current Chilean law. Rates of contributing to the privatized pension program are low among uncovered sector workers.

The structure of the Chilean pension system can be described as a "threepillar public/private system," in the terminology of the World Bank (1994). This paragraph draws on a description of the pension system given in Arenas de Mesa et. al. (2006).The first pillar is the public safety-net component that consists of a (i) means-tested welfare pension (pensiones asistenciales, or PASIS) for the poor, (ii) a state guaranteed minimum pension (MPG) for participants in the Administradoras de Fondos de Pensiones (AFPs, or pension fund managers) who have at least 20 years of contributions, and (iii) a public defined benefit system that administers the old PAYGO defined benefit program (closed since 1980 to new entrants). The second pillar of the pension system, which has received the most attention, consists of the mandatory defined contribution program known as the AFP system. This is a national savings program for all wage and salary workers that is intended to provide participants with old-age benefits (it also provides a life insurance and disability benefit as part of the mandatory program). ${ }^{2}$ The third pillar

\footnotetext{
${ }^{2}$ When the new program was announced, existing workers were required to decide whether to remain in the old INP system or to move to the new system. Those who moved to the new system received credit for INP contributions known as a transferable Recognition Bond (RB). The new AFP system is mandatory for all new wage and salary workers joining the labor force as of 1981, but affiliation remains optional for self-employed workers.
} 
of the Chilean pension system is a voluntary component, whereby affiliates who wish to pay more than the mandated pension contribution may do so, with their voluntary contributions receiving some tax benefits. Only a very small fraction of workers make contributions over the obligatory level.

In March 2006, the Chilean president, Michele Bachelet, appointed an independent commission of experts to study and propose improvements to the pension system, with the goals of increasing coverage and contribution rates. Two of the recommendations were to extend the state's safety net by reducing the required length of time needed to qualify for the minimum pension benefit guarantee and by increasing the amount of income allowed to qualify for the means-tested PASSIS program. A third recommendation was to make contributions mandatory for self-employed workers. Some of these proposed reforms were passed by Congress in January, 2008.

The aim of this paper is to study how individuals' labor force and pension contribution behavior is affected by the rules governing the system. We use a dynamic model of labor force sector participation, retirement and contribution patterns to study these effects. The dynamic model takes into account that individuals working in different labor market sectors face different wage processes, that future wage and preference shocks are uncertain at the time of making decisions, and that contributions rules differ for covered and uncovered sector workers. The model is estimated using data from from the 2002 Historia Laboral y Seguridad Social (HLLS) survey and the 2004 Enquesta Proteccion Sociale (EPS) follow up survey. ${ }^{3}$ The data contain demographic

\footnotetext{
${ }^{3}$ These data were gathered in 2002 and 2004 by the Microdata Center of the Department of Economics of the Universidad de Chile under the direction of David Bravo. The data collection was in part supported by an NIH grant, for which Petra Todd was the PI.
} 
and labor market information on 17,246 individuals age 15 or older, including information on household characteristics, education, training and work history, pension plan participation, savings, as well as more limited information on health, assets, disability status and utilization of medical services. This study focuses on men, in part because many women do not work and to avoid the consideration of the timing of fertility decisions and they interact with working decisions. There are also extensive questions that are aimed at assessing financial literacy and eliciting individual's attitudes towards risk. We complement the survey data with linked administrative data on pension contributions and fees paid that we obtained from the pension fund regulatory agency, market data on the performance of various pension funds (their returns, costs and profits), and data on the fees/commissions of pension funds that were in operation at different points in time. Through the linking of the household demographic data to the administrative history of individual pension fund decisions, we are able to carry out a detailed micro-economic analysis of decision-making relevant to pension accumulations.

This paper is organized as follows. Section 2 reviews the related literature. Section 3 provides more information on the Chilean pension system. Section 4 describes the dataset and presents descriptive statistics for the analysis sample. Section 5 presents the behavioral model and describes the solution and estimation method. Section 6 presents the estimation results and evidence on goodness of fit. Section 7 uses the estimated model to carry out several policy experiments related to changes in the rules governing the pension system and section 8 concludes. 


\section{Literature Review}

This work builds on previous studies that develop and estimate dynamic behavioral models for the purpose of studying how social security and pension rules affect labor supply and retirement behavior, most notably Gustman and Steinmeier (1986), Rust and Phelan (1997), French (2002), and Van der Klaauw and Wolpin (2005). These studies use data from individuals whose retirement benefits are defined benefit not defined contribution. Under a defined benefit plan, the retirement benefits typically depend on age of retirement, an average of the past earnings and years of service. In a defined contribution scheme, such as that in Chile, the retirement benefits depend on contribution accumulations and investment returns.

An early paper by Gustman and Steinmeier (1986) develops and estimates a life-cycle model that they use to study how social security and pension benefits affect working and retirement behavior. Individuals may be working full-time, be partially retired or fully retired. The model includes the fact that individuals in partial retirement obtain a lower wage rate than those working full time. Once the model is estimated, it is used to simulate retirement behavior. The simulations of the percentages of individuals who are working full-time, partially retired, and fully retired are very similar to those observed in the data, with peaks in retirement percentages at age 62 and 65 . These peaks occur because of effects that social security and pension benefits have on wages and on retirement behavior. Their paper was the first empirical study to treat each year as a separate period for obtaining optimal labor supply paths over the entire life cycle. In our paper we also obtain these 
paths and examine how changes in retirement benefits affect labor decisions of young individuals.

Rust and Phelan (1997) study how social security and Medicare affect retirement behavior when some individuals face borrowing constraints and do not have access to annuities and health insurance. They develop and estimate a dynamic programming model about individuals' decisions on labor supply and application for social security benefits that incorporates constraints imposed by incomplete markets and allows for uncertainty in future earnings. They find that the peak in retirement at 62 is best explained by the borrowing constraints and that the peak at 65 is explained by incomplete markets on annuities and health insurance and the fact that, for those older than 65, Medicare is available after application for social security benefits.

Most recent empirical analysis of how social security regulations affects retirement behavior incorporate savings behavior and heterogeneity, for instance, French (2002) and Van der Klaauw and Wolpin (2005). As opposed to the earlier literature, these authors use the estimated model to conduct various policy experiments to evaluate not only the effects on labor supply and retirement behavior of older workers but also on that of workers younger than 62 years old. Changes in the size of social security benefits and in the legal age of retirement are some of the policy experiments they conduct. French (2005) finds that the effects of those changes on working decisions of younger individuals are smaller than those of old workers. Van der Klaauw and Wolpin (2005), who model the decisions of married and single individuals, find that, in general, the behavior of singles is more affected by those changes than that of married individuals. Although we do not incorporate 
savings, outside of retirement savings in this paper, the model we use in this study also includes heterogeneity. As in the above two papers, we are very interested in evaluating the behavior of young individuals. The main difference between the models described above and the model used in this paper is that we model not only the labor supply decision but also the choice of informal and formal labor market and the contribution decision.

Most empirical studies of the Chilean pension system analyze aggregate and macro data. For instance Corsetti and Schmidt-Hebbel (1995) use an overlapping generations model with endogenous growth and formal-informal production sectors to show how the privatization of the pension system explains the increasing private savings and rising growth. The authors suggest that switching from a pay-as-you-go system to a fully funded system creates incentives to move employment to the more efficient formal sector.

There are a few papers that use micro data, but mostly for descriptive purposes. Areanas de Mesa et. al. (2004) examine coverage of the Chilean pension system. They use the 2002 round of the Historia Laboral y Seguridad Social (HLLS) survey to estimate the density of contributions, which is calculated by adding the number of months of contributions since January 1980 and dividing it by the total number of months since January, 1980. That paper concludes that the average density $52 \%$ of months, which implies substantially lower replacement rates for representative individuals upon retirement than would a hypothetical contribution density of $80 \%$ as assumed in previous studies that forecast old-age pensions. In a subsequent paper, Arenas de Mesa et. al. (2006) use the same data linking information on contributions to the administrative records provided by the pension fund 
regulatory agency, which are the same administrative data used in this paper. They show that, over their lifetimes, men contribute more than women and self-reported payments indicate higher contribution levels than those observed in the contribution records. Also, they note that people usually do not contribute during periods of unemployment or self-employment. They also provide evidence that most workers know very little about the rules and regulations of the pension system.

Motivated by the findings in Arenas de Mesa et al (2004, 2006), we are interested in studying how pension investment decisions in Chile depend on pension system rules. In particular, we evaluate the effect of changing the rules of the system on employment in the covered sector and uncovered sector and on contribution decisions.

\section{The Chilean Pension System}

The new Chilean Pension System known as the "AFP system" is based on individual capitalization. Each member of the system has an individual account where contributions are deposited. The accounts are managed by a Pension Fund Administrator (AFP). The AFPs are competitive firms whose purpose is to invest the pension funds in the capital market and to provide to affiliates their corresponding retirement benefits since 2002, each AFP must offer five funds with different levels of risk, and therefore, different returns. Prior to 2002, only two different risk levels were offered. Members of the system may change from one AFP to another whenever they want without incurring any monetary switching cost. ${ }^{4}$

\footnotetext{
${ }^{4}$ There are currently six AFPs operating in Chile.
} 
For those members of the AFP system who are working, it is mandatory to pay the following monthly contributions calculated as a percentage of the their taxable wage and other taxable income with an upper limit of $60 \mathrm{UF}$ ${ }^{5}$ : 1) $10 \%$ for the pension fund, 2) $7 \%$ for health services, 3) around $0.8 \%$ to finance disability and survivorship insurance, and 4) around $1.6 \%$ for the AFP expenses and profits. Besides the last two, which together are called the percentage commission, there is a fixed commission charged every month. The commissions are set by each Administrator.

Pensions are financed with the resources accumulated in the individual account. If a member of the AFP system does not save enough to obtain a pension equivalent to the minimum pension, the State finances the remainder provided the individual has accumulated 20 years of contribution by his retirement age. The legal age of retirement is 65 for men and 60 for women. Early retirement is allowed, provided that the retiree can obtain a pension equal or greater than half his average earnings in the last 10 years and equal or greater than 1.1 times the minimum pension guaranteed by the State. ${ }^{6}$

Membership of the AFP system is mandatory for those individuals in the covered sector employed for the first time after January 1983 and voluntary for the self-employed. Individuals that started working before January 1983

\footnotetext{
${ }^{5}$ The value of the UF as of December 2004 was $\$ 17,317$ pesos (US\$31)

${ }^{6}$ At retirement, a member can choose from three pension payout options: 1) programmed withdrawals, the member keeps his savings in his individual account and withdraws annual amounts (in monthly payments). The AFP manages the account and recalculates the annual amount every year; 2) life annuity, the member purchases a life annuity from a life insurance company where his savings are transferred. The Company promises to make monthly payments until the death of the member; 3) temporary income with deferred life annuity, the member keeps part of his savings in his individual account and purchases a life annuity with the other part. He withdraws annual amounts until he starts to receive the life annuity.
} 
and belonged to the old pay-as-you-go system have the right, but not the obligation, to switch systems. Workers who switch to the individual capitalization system obtain their Recognition Bond, an instrument issued by the State that represents the contributions paid to the pay-as-you-go system. The bond becomes payable when the legal age of retirement is reached and it is deposited in the worker's individual account. The pensions and contributions of those that stayed in the old system are managed by the Institute of Social Security Normalization (INP) which was created in 1980.

\section{The Data}

We use data from from the 2002 Historia Laboral y Seguridad Social (HLLS) survey and the 2004 Enquesta Proteccion Sociale (EPS) follow up survey. Both surveys constitute the longitudinal data set that contains information at the individual level on a representative sample of the working-age population in Chile. The data set covers around 17,000 respondents: 14,000 affiliated either with the pay-as-you-go system or the AFP system at any time since 1981, and 3,000 not affiliated to any pension system. The respondents were either working, unemployed, out of the labor force, or officially retired. The data contain information on affiliation status, employment history since 1980, pension contributions, retirement plan participation, savings, education, health, family background, family income, assets, and capital. The 2006 follow-up has been already administered and an additional follow-up round is planned for 2008. Half of the respondents are men. The most relevant information collected in the EPS survey for this study is the retrospective data on employment, non-employment, and unemployment spells, 
available back to 1980 .

The EPS information can be linked to administrative records on mandatory and voluntary monthly contributions, monthly wages, changes between AFPs and delayed payments. There are also data on the value of the Recognition Bond for those who switched systems and information on the type of pension plan that retirees receive. For the purposes of this study, the most important administrative information is the histories of monthly contributions and wages for those that contribute since January 1981. The Surveys linked to administrative records provide the essential data base for studying the effect of the rules of the pension system on employment and contribution decisions.

Because many women do not work in the paid labor market for long periods of time, this study focuses on men. The parameters of the model are estimated only the information on men between 18 and 39 years old in 2004 for the following reasons: 1) it is assumed that men can start contributing at 18, the age at which they should finish high school; 2) membership of the AFP system is mandatory for those entering the workforce for the first time after January 1983. By restricting the analysis to younger individuals, we ensure that these individuals never paid contributions into the old system, for which no records are available.

\subsection{Descriptive Statistics}

The sample used in the estimation of the model consists of 2,517 men between 18 and 39 years old in 2004 with an average age of 30.4 who, by 2004, already 
finished their studies. ${ }^{7}$ Regarding the region of residence, $37.8 \%$ of them live in a metropolitan area. The distribution of the individuals by education is the following: $12.4 \%$ of them did not complete the basic education (8 years), $32.6 \%$ have between 8 and 11 years of education, and $42.2 \%$ completed high school (12 years of education). The other $12.8 \%$ studied at least one year of college. On average, they have 10.7 years of education. With regard to marital and health status in 2004, 66.6\% are already married and 9.3\% have been diagnosed with a chronic disease, such as diabetes, hypertension, etc. Table 1 summarizes the socio-demographic characteristics of the sample.

\begin{tabular}{lcc}
\multicolumn{2}{c}{ Table 1: Socio-demographic } & Characteristics \\
\hline & Percentage \\
\hline Residence in metropolitan area in 2004 & $37.8 \%$ \\
Bad health in 2004 & $9.3 \%$ \\
Married in 2004 & \multicolumn{2}{c}{$66.6 \%$} \\
\hline & Mean & Std. Dev. \\
\hline Age in 2004 & 30.4 & 5.6 \\
Years of education in 2004 & 10.7 & 3.0 \\
\hline
\end{tabular}

Table 2 presents statistics relevant to LFP and pension contribution. On average, individuals have worked $72.6 \%$ of the time since completing their education. From that percentage, $26.6 \%$ of the time was spent in a covered sector job and the other $46.0 \%$ in the uncovered sector. The mean of annual earnings in the covered sector (2.2 million pesos) is higher than that in the uncovered sector (1.5 million pesos).

The density of contributions is defined as the percentage of quarters of contribution of the total number of quarters elapsed since an individual fin-

\footnotetext{
${ }^{7}$ The education decision is not included in the model. Individuals enter the sample once they finished studying
} 
ished his studies. The mean of the density of contributions at the beginning of the year is only $30.3 \%$. From that $30.3 \%, 26.5 \%$ corresponds to mandatory contributions paid while working in the covered sector and the other $3.8 \%$ comes from voluntary contributions while in the uncovered sector. Although individuals work in average $46.0 \%$ of the time in an uncovered job, they only rarely make voluntary pension contributions on that job.

\begin{tabular}{lcc}
\multicolumn{3}{c}{ Table 2: Labor and Contribution Statistics * } \\
\hline Labor sector participation & Mean & Std. Dev. \\
Working & $72.6 \%$ & $32.3 \%$ \\
Covered sector & $26.6 \%$ & $29.1 \%$ \\
Uncovered sector & $46.0 \%$ & $35.0 \%$ \\
Not working & $27.4 \%$ & $32.3 \%$ \\
Annual earnings in thousands of pesos** & & \\
$\quad$ Covered sector & 2,225 & 1,723 \\
$\quad$ Uncovered sector & 1,534 & 1,243 \\
Contribution to the pension & $30.3 \%$ & $29.4 \%$ \\
$\quad$ Density of contributions & $26.6 \%$ & $29.1 \%$ \\
$\quad$ Covered sector & $3.8 \%$ & $10.5 \%$ \\
Uncovered sector & & \\
\hline
\end{tabular}

* counting since they finished studying and until 2004

** 1,000 pesos $=$ US $\$ 1.785,2004$ pesos

Tables 3 to 5 present average earnings, the average of accumulated quarters of work and contributions, the average percentage of time working, and the average density of contributions in both labor sectors by age groups. As shown in Table 3, after-tax earnings in the covered sector are between $40 \%$ and $50 \%$ greater than earnings in the uncovered sector for every age group. 
Table 3: Earnings in the Covered and Uncovered Sectors by Group of Age *

\begin{tabular}{ccccc}
\hline & \multicolumn{4}{c}{ Thousands of Pesos* } \\
\hline & \multicolumn{2}{c}{ Covered } & \multicolumn{2}{c}{ Uncovered } \\
\hline Age Group & Mean & Std. Dev. & Mean & Std. Dev. \\
\hline $18-20$ & 1,223 & 687 & 874 & 699 \\
$21-25$ & 1,727 & 1,122 & 1,230 & 907 \\
$26-30$ & 2,542 & 1,912 & 1,694 & 1,283 \\
$31-35$ & 2,965 & 2,052 & 1,915 & 1,445 \\
$36-39$ & 3,077 & 1,979 & 2,140 & 1,507 \\
\hline
\end{tabular}

* counting since individuals finished studying and until 2004

** 1,000 pesos US $\$ 1.785,2004$ pesos

Table 4 shows that, although earnings are higher in the covered sector, the proportion of time working in the uncovered sector is greater than that in the covered sector at all ages. However, the difference between these proportions decreases with age. The group of individuals between 36 and 39 years old have accumulated more than 65 quarters of work in both sectors. Had they contributed every quarter, they would only need only 15 more quarters of contributions to be eligible for the minimum pension. However, this group has accumulated only 31.3 quarters of contribution on average. The density of contributions in the uncovered sector, where contributions are voluntary, is very low for every age group (see Table 5). It increases slightly with age, from $1.6 \%$ to $5.5 \%$. 
Table 4: Accumulated Quarters of Work and Percentage of Time Working in the Covered and Uncovered Sectors by Group of Age*

\begin{tabular}{ccccc}
\hline & \multicolumn{4}{c}{ Means } \\
\hline Age Group & \multicolumn{3}{c}{ Covered } & \multicolumn{3}{c}{ Uncovered } \\
\hline $18-20$ & 0.5 & $8.5 \%$ & 2.4 & $40.3 \%$ \\
$21-25$ & 4.2 & $21.3 \%$ & 8.7 & $45.3 \%$ \\
$26-30$ & 12.2 & $33.5 \%$ & 17.6 & $47.2 \%$ \\
$31-35$ & 20.9 & $38.2 \%$ & 27.7 & $48.7 \%$ \\
$36-39$ & 27.3 & $37.5 \%$ & 38.6 & $52.2 \%$ \\
\hline
\end{tabular}

${ }^{*}$ Counting since individuals finished studying

Table 5: Accumulated Quarters of Contribution and Density of Contribution in the Covered and Uncovered Sectors by Group of Age* Means

\begin{tabular}{ccccc}
\hline Age Group & \multicolumn{2}{c}{ Covered } & \multicolumn{2}{c}{ Uncovered } \\
\hline $18-20$ & 0.5 & $8.5 \%$ & 0.1 & $1.6 \%$ \\
$21-25$ & 4.2 & $21.3 \%$ & 0.6 & $3.3 \%$ \\
$26-30$ & 12.2 & $33.5 \%$ & 1.7 & $4.4 \%$ \\
$31-35$ & 20.9 & $38.2 \%$ & 2.9 & $5.1 \%$ \\
$36-39$ & 27.3 & $37.5 \%$ & 4.0 & $5.5 \%$ \\
\hline
\end{tabular}

*Counting since individuals finished studying

\section{The Model}

The model we estimate and use for the counterfactual simulations builds on a model developed in Velez-Grajales (2008). It represents an individual's decision problem with regard to dynamic labor market participation and pensions contributions. The model starts at the age the individual finishes his studies, $a_{o}$, and ends at age $\bar{A}=85$. The individual makes decisions until retirement, at age $A$. At the beginning of each period $a \leq A$, he observes his health status and marital status and receives wage offers from both labor market sectors, the covered sector and the uncovered sector, and decides how many 
quarters to work, how many quarters not to work, or to retire. We define the covered sector as the one where workers have signed employment contracts and pension contribution is compulsory. The uncovered sector includes jobs where workers have not contributing the pensions program is voluntary. signed a contract or self-employment jobs and The individual chooses how many quarters to work. In the covered sector he has to contribute the same number of quarters as he works. In the uncovered sector, the contribution decision is also assumed to be made by quarter; so he has to decide how many quarters to contribute from the quarters he works. Finally, it is assumed that an individual does not contribute when not working.

Each period $a \leq A$, the individual chooses one of the mutually exclusive available combinations of labor and contribution decisions or retirement, $k \in$ $K_{a}$, to maximizes his remaining expected present discounted lifetime utility:

$$
V\left(\Omega_{a}, a\right)=\max _{k \in K_{a}} E\left(\sum_{\tau=a}^{\bar{A}} \delta^{\tau-a}(1-D(\tau))^{\tau-a} U^{k}(\tau) \mid \Omega_{a}\right),
$$

where $\Omega_{a}$ denotes the space at age $a, \delta$ is the discount factor and $D$ is the probability of dying next period.

The individual's utility function, at each age $a$, is given by:

$$
U_{a}=U\left(C_{a}, l_{a}, s_{a}^{u} ; M_{a}, H_{a}, \varepsilon_{a}^{C}, \varepsilon_{a}^{l}, \mu\right)
$$

The term $C_{a}$ represents the individual's consumption at age $a$. The individual obtains non-pecuniary utility from quarters not working and for quarters working in the uncovered sector, $l_{a} \epsilon\{0,1,2,3,4\}$ and $s_{a}^{u} \epsilon\{0,1,2,3,4\}$, respectively. Utility also depends on marital status and health status. The individual has good health, $H_{a}=0$, until diagnosed with a chronic disease, after 
which $H_{a}=1$. Regarding marriage, he can be married, $M_{a}=1$, or single, $M_{a}=0$. It is assumed that once an individual gets married he stays married.* The probabilities of being diagnosed with a chronic disease or getting married depend on age, years of education, previous health status, and unobserved individual-specific factors. The terms $\varepsilon_{a}^{C}, \varepsilon_{a}^{l}$ are age-varying shocks to the marginal utilities of consumption and leisure. The term $\mu$ is a vector of unobserved individual-specific factors that affect preferences for consumption and time working.

Consumption at age $a<A$ is equal to earnings minus contributions if the individual works, or an unemployment benefit. At ages $a \geq A$ it equals the pension:

$$
C_{a}=\left\{\begin{array}{rr}
s_{a}^{c} \frac{w_{a}^{c}}{4}[1-(\tau+\phi)]+\frac{w_{a}^{u}}{4}\left[s_{a}^{u}-q_{a}^{u}(\tau+\phi)\right]+C_{M} I\left(l_{a}=4\right), & \forall a<A ; \\
P_{a}, & \forall a \geq A,
\end{array}\right.
$$

where $w_{a}^{c}$ is the annual wage paid to the covered worker, $w_{a}^{u}$ is the annual wage paid to the uncovered worker, and $b$ is the unemployment benefit the worker receives when he does not work that year. ${ }^{8}$ The contribution rate is $10 \%$ of taxable earnings, $\tau=0.1$. The average fees and commissions that AFPs charge per year are represented by $\phi$.

Wage offers are sector-specific, $w^{j}$, where $j=c$ is covered and $j=u$ is uncovered. The wage offer for an individual at age $a$ is:

$$
w_{a}^{j}=\rho^{j} K_{a}^{j}\left(E, G, T_{a}^{j}, T_{a}^{-j}, \varepsilon_{a}^{j} ; \mu\right),
$$

where $\rho^{j}$ is a sector-specific skill rental price, and $K_{a}^{j}$ is the individual's stock

\footnotetext{
${ }^{8}$ Incorporating savings other than the pension contributions greatly increases the complexity of the estimation problem. Moreover, few people report other types of savings in the data.
} 
of human capital at age $a$ that varies with the job market sector. The individual accumulates capital through years of work experience. The cumulative years worked in the sector $j$ up to age $a$ is represented by $T_{a}^{j}$ (tenure). $\varepsilon_{a}^{j}$ is an age-varying shock that differs by sector and $\mu$ is a vector of unobserved individual-specific factors that affect wage offers. Denote by $W_{a}=\left[w_{a}^{c}, w_{a}^{u}\right]$ the vector that includes the wage offers received by an individual at the beginning of period $a$.

The individual knows the following rules of the pension system:

1) Pensions are financed with the funds accumulated in the individual investment accounts. Upon payout, it is assumed that the individual purchases a life annuity and gets monthly payments until death at 85 years old. The amount of the pension at each age $a$ depends on the account balance and an annuity factor that depends on age and marital status.

2) The account balance at the end of the period $a$ is $B_{a}=\left(B_{a-1}+\Gamma_{a}\right)(1+$ $R$ ), where $\Gamma_{a}$ is the amount of contributions during period $a$, and $R$ represents the average annual rate of return of the pension fund which varies every year. ${ }^{9}$

3) When the funds in the account are insufficient to finance the minimum pension set by the government, $P_{M}$, the state guarantees the payment of the minimum pension to members that fulfill the requirement of 20 years of contribution (80 quarters).

4) The legal age of retirement for men is 65 years old, but retirees have the option to take early retirement provided that the pension is higher than half the average earnings in the last 10 years and higher than 1.1 times the

\footnotetext{
${ }^{9}$ The expected annual rate of return is $E[R]=\kappa$, then $R=\kappa+\varepsilon^{R}$, where $\varepsilon^{R}$ is an annual-varying shock.
} 
minimum pension.

5) Individuals who are not members of any pension system have the right to get a basic pension, called PASIS ${ }^{10}$, that is financed by the government. To be eligible to get the PASIS the individual has to be at least 65 years old and have an average wage lower than twice the minimum pension amount. ${ }^{11}$ The size of the PASIS is half of the minimum pension.

The initial conditions of the model are years of education, $E \epsilon\{0,1, \ldots, 18\}$, and region of residence, $G \epsilon\{0,1\}$, which takes the value of 1 if the individual lives in the metropolitan area. The state variables at age $a$ are the initial conditions of the model plus age, year, previous marital status, previous health status, years of work experience in each labor market sector, quarters of contribution, balance in the individual account, average wage of last ten years, and the vector of shocks $\epsilon_{a}$. We denote the state space at age $a$ by $\Omega_{a}$,

$$
\Omega_{a}=\left\{a, E, G, M_{a-1}, H_{a-1}, T_{a}^{c}, T_{a}^{u}, Q_{a}, B_{a}, \bar{W}_{a}, \epsilon_{a}\right\}
$$

The age-varying shocks to consumption, leisure, the wage offer in the covered sector, the wage offer in the uncovered sector, and the rate of return are assumed to be iid with mean zero, jointly normally distributed, and serially uncorrelated. $^{12}$ Additionally, the vector of unobserved individualspecific factors is assumed to be independently distributed from the vector of stochastic shocks.

\footnotetext{
${ }^{10}$ PASIS stands for Pension Asistencial (welfare pension)

${ }^{11}$ To be eligible for the PASIS individuals have to have an income less than $50 \%$ of the minimum pension or no income at all. Here the eligibility depends on the level of the average wage in the last ten years

${ }^{12}$ There are also implicit shocks to the probabilities of marriage and bad health, which are assumed to be independently distributed from the explicit shocks considered.
} 
The functional forms for the utility, the wage offers, and the probabilities of being in bad health and of getting married are described in Appendix A.

\subsubsection{Model Solution}

The model is solved by backwards recursion, starting from the last period the individual makes decisions, $A$, to the initial period $a_{0}$. It is assumed that everyone retires by age 70 . The terminal value is the discounted value of the remaining lifetime utility, which depends on the pension and therefore on the state space at age of retirement. ${ }^{13}$ At period $A-1$, the individual chooses the option that maximizes his period utility plus the terminal value given the state space $\Omega_{A-1}$. Then at period $A-2$, he calculates the alternative value functions, integrating over the distribution of the shocks at period $A-1$, for every option and every point in the state space, that is, the expected value next period $A-1$ given the decision $k \in K_{A-2}$ and every state point in $\Omega_{A-2}$. This is called the Emax function (Keane and Wolpin (1994, 1997)).

It is not possible to calculate the expected value for every point in the state space given its size and because some of the state variables are continuous,and the model does not have a closed-form solution. We therefore obtain a numerical solution using an approximation method to obtain the value of the Emax function as proposed in Keane and Wolpin (1994, 1997). The values computed at a subset of points of the state space are used to approximate the Emax function by a polynomial in the state variables. To calculate the expected value we use Monte Carlo integration. ${ }^{14}$

\footnotetext{
${ }^{13}$ It is assumed that individuals discount their utility until they are 85 years old.

${ }^{14}$ The model is solved using 2,600 state space points and 40 draws for the shocks.
} 


\subsubsection{Model Estimation}

The parameters of the model are estimated using the Simulated Maximum Likelihood method. The likelihood for a sample of $I$ individuals is the product of the $I$ probabilities of the outcomes being observed each period up to an age, given the initial conditions and the unobserved heterogeneity of each individual. The observed outcomes include the following: a) the choice $k$ that is a combination of labor and contribution decisions, b) the health status $H$ that can be bad or good, c) the marital status $M$ that can be single

or married, d) the wage offers $\left\{w^{c}, w^{u}\right\}$ received form each sector, and e) the annual rate of return $R$. The vector of outcomes at period $a$ is represented by $O_{a}=\left\{k_{a}, H_{a}, M_{a}, w_{a}^{c}, w_{a}^{u}, R_{a}\right\}$. The vector of initial conditions is the state space at period $a_{0}$ denoted by $\Omega_{a_{0}}$. Assume that the individual-specific unobserved characteristics identifies 2 types of individuals in the population, $\mu_{1}$ and $\mu_{2}$. Then, heterogeneity is represented by the vector of types $\mu=\left\{\mu^{1}, \mu^{2}\right\}$.

The likelihood for the sample of $I$ individuals observed from their initial period $a_{0}^{i}$ to period $\hat{a}^{i}$ is

$$
\prod_{i=1}^{I} P\left(O_{\hat{a}^{i}}, O_{\hat{a}^{i}-1}, \ldots, O_{a_{0}^{i}} \mid \Omega_{a_{0}^{i}}, \mu\right) .
$$

Because the type is assumed to be known by the individual but unobserved by the econometrician, it is integrated out. We also assume that the initial conditions are exogenous conditional on type. The sample likelihood is:

$$
\prod_{i=1}^{I} \sum_{t=1}^{2}\left\{P\left(O_{\hat{a}^{i}}, O_{\hat{a}^{i}-1}, \ldots, O_{a_{0}^{i}} \mid \Omega_{a_{0}^{i}}, \mu^{t}\right) \times P\left(\mu^{t} \mid \Omega_{a_{0}^{i}}\right)\right\},
$$

where $P\left(\mu^{t} \mid \Omega_{a_{0}^{i}}\right)$ is the probability of individual $i$ of being of type $t$. These 
type probabilities are functions of the initial conditions and are also estimated.

Due to the shocks' serial independence assumption, the probability of observing the outcomes up to some age given the initial conditions and the type $t$ for an individual $i$ can be written as:

$$
P\left(O_{\hat{a}^{i}} \mid \Omega_{\hat{a}^{i}}, \mu^{t}\right) P\left(O_{\hat{a}^{i}-1} \mid \Omega_{\hat{a}^{i}-1}, \mu^{t}\right) \ldots P\left(O_{a_{0}^{i}} \mid \Omega_{a_{0}^{i}}, \mu^{t}\right) .
$$

In the calculations of the probabilities it is necessary to integrate over the shocks to to consumption, leisure, the wage offer in the covered sector, the wage offer in the uncovered sector, and the rate of return. A difficulty that has to be considered in calculating the likelihood is that some of the wages are missing in the data. This problem is solved by integrating out over all possible wages.

The maximization of the likelihood function iterates between the solution of the model and the computation of the likelihood function. Because the available options and choices in the model are discrete, we require the use of a maximization algorithm that does not assume differentiability and we use the simplex method. The identification of the parameters in the model is obtained from the combination of exclusion restrictions and the functional forms assumed.

\section{Estimation Results and Model Fit}

\subsection{Parameter Estimates}

The functional forms for the utility, the wage offers, the probabilities of being in bad health and of getting married are presented in Appendix A. The 
estimates of the 51 estimated parameters are shown in Appendix B. ${ }^{15}$ Looking at the estimates we observe some interesting aspects about the structure of the model. Note in the first part of table 16 that $\theta_{2}>0$ which implies that consumption and leisure are substitutes. As expected, the marginal utility of consumption decreases with bad health $\left(\theta_{3}<0\right)$ as opposed to the marginal utility of leisure which increases with bad health $\left(\theta_{8}>0\right)$. Single and young individuals value leisure more than the married older ones $\left(\theta_{6}, \theta_{7}>0\right)$, which explains why young individuals work less as the simulations below show. However, for those who work the utility of working in the uncovered sector is higher than that of working in the covered sector $\left(\theta_{10}>0\right)$.

There is a positive effect of work experience on wage offers in both labor sectors; however, the effect is more important in the covered sector than in the uncovered sector. Moreover, having worked in the covered sector has a very small effect on wages offered in the uncovered sector. The estimates about region of residence imply that living in the metropolitan area has a higher positive effect on wage offers in the uncovered sector than on those in the covered sector.

The probability of marriage increases with age and years of education, although the positive relationship with age is stronger than that with years of education. Regarding the probability of being in bad health, age has a positive effect and education has a negative effect.

\footnotetext{
${ }^{15}$ The discount factor $\delta$ is not estimated because it is not possible to identify it alone. We use a $\delta=0.9$
} 


\subsection{Model Goodness of Fit and Base-Line Model Statis- tics}

This section presents the model's goodness of fit to the data. As noted earlier, the model is estimated using data on men at ages 18-39. The model fits the data well in several dimensions as shown in, Tables 6 to 9 . Table 6 presents the comparison of the average accumulated number of quarters of work per sector by groups of age. The model predicts quarters of work very well, although the predictions are slightly higher than those observed in the data for the covered sector and slightly lower than those observed for the uncovered sector. The predictions of accumulated quarters not working are also higher than in the data. For age groups starting at 40 years old, only simulated data are available.

Table 6: Accumulated Quarters of Work in the Covered and Uncovered Sectors and Quarters not Working

\section{Data/Simulated}

\begin{tabular}{|c|c|c|c|}
\hline Age Group & $\begin{array}{c}\text { Covered } \\
(\text { mean })\end{array}$ & $\begin{array}{c}\text { Uncovered } \\
(\text { mean })\end{array}$ & $\begin{array}{c}\text { No work } \\
\text { (mean) }\end{array}$ \\
\hline $18-25$ & $3.1 / 3.9$ & $\begin{array}{l}6.8 / 6.5 \\
\end{array}$ & $5.1 / 5.2$ \\
\hline $26-32$ & $13.7 / 14.7$ & $19.2 / 18.2$ & $7.0 / 8.5$ \\
\hline 33-39 & $24.4 / 27.9$ & $33.3 / 31.0$ & $7.4 / 10.2$ \\
\hline $40-44$ & $-\quad / 39.3$ & $-/ 42.1$ & $-\quad / 11.7$ \\
\hline $45-49$ & $-\quad / 48.6$ & /51.1 & $/ 13.4$ \\
\hline $50-54$ & $-\quad / 57.3$ & $/ 59.9$ & $/ 15.9$ \\
\hline $55-59$ & $-\quad / 65.4$ & $-\quad / 68.5$ & $-/ 19.3$ \\
\hline $60-64$ & $-\quad / 72.7$ & $-\quad / 76.8$ & $-/ 23.6$ \\
\hline $65-69$ & $-\quad / 79.0$ & $-\quad / 84.0$ & $-\quad / 30.1$ \\
\hline
\end{tabular}

Table 7 shows how the model fits the data on accepted annual wages by sector. The average predicted wages are close to actual wages for all age 
Table 7: Accepted Annual Wages in the Covered and Uncovered Sectors

\begin{tabular}{|c|c|c|}
\hline & \multicolumn{2}{|c|}{ Data/Simulated } \\
\hline Age Group & $\begin{array}{l}\text { Covered } \\
\text { (mean) }\end{array}$ & $\begin{array}{l}\text { Uncovered } \\
\text { (mean) }\end{array}$ \\
\hline $18-25$ & $1,640,718 / 1,648,139$ & $1,124,914 / 1,340,707$ \\
\hline $26-32$ & $2,675,647 / 2,378,733$ & $1,724,703 / 1,917,354$ \\
\hline 33-39 & $3,039,368 / 3,230,492$ & $1,993,377 / 2,251,030$ \\
\hline $40-44$ & $-\quad / 3,775,020$ & $-\quad / 2,529,600$ \\
\hline $45-49$ & $/ 3,992,639$ & $/ 2,728,268$ \\
\hline $50-54$ & $/ 4,056,046$ & $/ 2,883,663$ \\
\hline $55-59$ & $/ 3,981,479$ & $/ 3,010,349$ \\
\hline $60-64$ & $/ 3,843,688$ & $/ 3,101,069$ \\
\hline $65-69$ & $/ 4,305,409$ & $/ 2,663,775$ \\
\hline
\end{tabular}

groups used in the estimation.

Table 8 presents the fit to the accumulated quarters of contribution. The model fits the patterns of quarters of contribution in the uncovered sector fairly well. However, the simulated accumulations for older ages are constant in that sector. For the covered sector, the model predicts slightly higher accumulations than those observed in the data. 
Table 8: Accumulated Quarters of Contribution in the Covered and Uncovered Sectors

\begin{tabular}{lcc}
\hline Age Group & \multicolumn{2}{c}{ Data/Simulated } \\
\hline Covered & $\begin{array}{c}\text { Uncovered } \\
\text { (mean) }\end{array}$ & (mean) \\
\hline $18-25$ & $3.1 / 3.9$ & $0.4 / 1.0$ \\
$26-32$ & $13.7 / 14.7$ & $1.8 / 2.3$ \\
$33-39$ & $24.4 / 27.9$ & $3.4 / 2.9$ \\
$40-44$ & $-/ 39.3$ & $-/ 3.1$ \\
$45-49$ & $-/ 48.6$ & $-/ 3.1$ \\
$50-54$ & $-/ 57.3$ & $-/ 3.1$ \\
$55-59$ & $-/ 65.4$ & $-/ 3.1$ \\
$60-64$ & $-/ 72.7$ & $-/ 3.1$ \\
$65-69$ & $-/ 79.0$ & $-/ 3.1$ \\
\hline
\end{tabular}

Table 9 shows the model's fit of the proportion of married men and of men in bad health. The model predicts very well the proportion married for all the age groups. The predictions for the proportion of men in bad health in the third group of age are slightly higher than that observed in the data, although the difference is small. In the other groups the predicted probability is the same as in the data. 
Table 9: Proportion of Married Men and Men in Bad Health

\begin{tabular}{ccc}
\hline & \multicolumn{2}{c}{ Data/Simulated } \\
\hline Age Group & $\begin{array}{c}\text { Married } \\
\text { (mean) }\end{array}$ & $\begin{array}{c}\text { In bad health } \\
\text { (mean) }\end{array}$ \\
\hline $18-25$ & $0.28 / 0.28$ & $0.02 / 0.02$ \\
$26-32$ & $0.70 / 0.70$ & $0.05 / 0.05$ \\
$33-39$ & $0.85 / 0.83$ & $0.08 / 0.09$ \\
$40-44$ & $-/ 0.84$ & $-/ 0.17$ \\
$45-49$ & $-/ 0.84$ & $-/ 0.26$ \\
$50-54$ & $-/ 0.84$ & $-/ 0.40$ \\
$55-59$ & $-/ 0.84$ & $-/ 0.58$ \\
$60-64$ & $-/ 0.84$ & $-/ 0.76$ \\
$65-69$ & $-/ 0.84$ & $-/ 0.90$ \\
\hline
\end{tabular}

\section{Counterfactual Policy Experiments}

\subsection{Minimum Pension}

The Minimum Pension Program is a welfare program sponsored by the government. It is provided to those members of the AFP system who are at least 65 years old (60 for women) and do not save enough in their individual accounts to obtain the current minimum pension amount set by the government. The State guarantees to finance the difference between the minimum pension and the pension obtained with the savings accumulated in the individual account provided the individual has contributed for 20 years. In January 2004, the minimum pension annual benefit was approximately $\$ 860,000$ pesos (approx. 1720 US Dollars).

To provide a larger fraction of the poor with a minimum pension in their old-age, the Chilean government proposed eliminating the requirement of 20 years of contributions for the poor. Starting July 2008 the fixed minimum 
pension benefit was replaced with a graduated minimum pension benefit called the Aporte Previsional Solidario de Vejez (APS). It is a complement to the pension obtained with the resources accumulated in the individual account that the State guarantees to finance. The size of the APS depends on the size of the contributory pension that each member can get; the larger the contributory pension the larger the APS. This complement will be provided to those members of the AFP system who fulfill only two requirements: to be at least 65 years old (60 for women) and to have a contributory pension lower than the Pension Máxima con Aporte Solidario, which is a maximum pension set by the government.

It is of policy interest to asses the impact of changing the rules regarding the Minimum Pension benefit. We use the estimated model to evaluate the impact on employment and contribution patterns of changes in the Minimum Pension rules similar to those already approved by the Congress at the beginning of this year. Individual decisions on labor participation and contribution to the pension are simulated under alternative scenarios. We focus on the effects on the decisions of individuals in the age range of our sample, for which the simulations would be expected to be most reliable.

\subsubsection{Years of contributions required to get the Minimum Pension}

Fiest we study the effect of changes in the quarters of contributions required to be eligible to obtain the Minimum pension. Table 10 compares the simulated accumulated quarters of work in both sectors for three different numbers of quarters required to be eligible to obtain the minimum pension: 80 (baseline), 60 and 40. The magnitude of the effects is greatest for younger 
people. For instance, the number of accumulated quarters of covered work for those at ages 18-25 increases from 3.9 to 4.1 when the requirement goes down to 60 quarters and from 3.9 to 4.3 when the requirement is 40 quarters. On the other hand, the accumulated quarters of work in the covered sector for those ages 60-64 increases only from 72.7 to 73.7 and from 72.7 to 75.2 respectively. Therefore, decreasing the number of quarters of contributions required to get the minimum pension from 80 to 60 , that is, by $25 \%$, increases work of the youngest group of individuals in the covered sector by $5 \%$ and when that requirement is lowered from 80 to 40 quarters, that is $50 \%$ lower, their work increases $10 \%$. In the other groups of age there are also increases in the accumulated quarters of work in the covered sector.

According to the simulations, the number of quarters of work in the uncovered sector does not drop as much as it rises in the covered sector, which implies that the observed response does not only come from individuals moving from the uncovered to the covered labor sector. In fact, most of the effect is explained by a decrease in the number of quarters individuals stay at home. 
Table 10: Accumulated Quarters of Work in the Covered and Uncovered Sectors and Quarters not Working

\begin{tabular}{ccccccccccc}
\hline $\begin{array}{c}\text { Req. Qr. } \\
\text { of Contr. }\end{array}$ & \multicolumn{4}{c}{$\mathbf{8 0}$} & \multicolumn{3}{c}{$\mathbf{6 0}$} & & & $\mathbf{4 0}$ \\
\multicolumn{9}{c}{ Baseline } \\
Age Group & Cov & Unc & NoW & Cov & Unc & NoW & Cov & Unc & NoW \\
\hline $18-25$ & 3.9 & 6.5 & 5.2 & 4.1 & 6.5 & 5.0 & 4.3 & 6.5 & 4.8 \\
$26-32$ & 14.7 & 18.2 & 8.5 & 15.2 & 18.0 & 8.2 & 15.8 & 17.8 & 7.9 \\
$33-39$ & 27.9 & 31.0 & 10.2 & 28.7 & 30.6 & 9.8 & 29.6 & 30.1 & 9.4 \\
$40-44$ & 39.3 & 42.1 & 11.7 & 40.2 & 41.5 & 11.3 & 41.4 & 40.8 & 10.9 \\
$45-49$ & 48.6 & 51.1 & 13.4 & 49.6 & 50.4 & 13.1 & 50.9 & 49.6 & 12.6 \\
$50-54$ & 57.3 & 59.9 & 15.9 & 58.4 & 59.2 & 15.5 & 59.8 & 58.3 & 15.0 \\
$55-59$ & 65.4 & 68.5 & 19.3 & 66.4 & 67.8 & 18.9 & 67.9 & 66.9 & 18.3 \\
$60-64$ & 72.7 & 76.8 & 23.6 & 73.7 & 76.2 & 23.2 & 75.2 & 75.3 & 22.6 \\
$65-69$ & 79.0 & 84.0 & 30.1 & 79.6 & 82.9 & 30.6 & 80.4 & 81.6 & 31.1 \\
\hline
\end{tabular}

Table 11 shows the effect of reducing the number of quarters required to get the minimum pension on contributions from 80 to 60 or 40 . Because it is mandatory to contribute while working in the covered sector, the effect on contributions in the covered sector is the same as the one described above for work in that sector. The effect on contributions in the uncovered sector for young people, the first three groups of age, is interesting. Even when work in that sector decreases, the quarters of contributions increases. When the requirement changes from 80 to 60 quarters, there is an increase of more than $30 \%$ and when it changes to 40 quarters, accumulated contributions increase by more than $70 \%$. Although the number of quarters of contributions in the uncovered sector is small, a change in the number of quarters required to get the minimum pension has important effects on the contribution decision. 
Table 11: Accumulated Quarters of Contributions in the Covered and Uncovered Sectors and Quarters not Working

\begin{tabular}{ccccccc}
\hline $\begin{array}{c}\text { Required Quarters } \\
\text { of Contributions }\end{array}$ & \multicolumn{3}{c}{$\mathbf{8 0}$} & \multicolumn{2}{c}{$\mathbf{6 0}$} & \multicolumn{2}{c}{$\mathbf{4 0}$} \\
& \multicolumn{3}{c}{ Baseline } \\
Age Group & Cov & Uncov & Cov & Uncov & Cov & Uncov \\
\hline $18-25$ & 3.9 & 1.0 & 4.1 & 1.3 & 4.3 & 1.7 \\
$26-32$ & 14.7 & 2.3 & 15.2 & 3.1 & 15.8 & 4.0 \\
$33-39$ & 27.9 & 2.9 & 28.7 & 4.1 & 29.6 & 5.4 \\
$40-44$ & 39.3 & 3.1 & 40.2 & 4.4 & 41.4 & 6.0 \\
$45-49$ & 48.6 & 3.1 & 49.6 & 4.5 & 50.9 & 6.1 \\
$50-54$ & 57.3 & 3.1 & 58.4 & 4.5 & 59.8 & 6.1 \\
$55-59$ & 65.4 & 3.1 & 66.4 & 4.5 & 67.9 & 6.1 \\
$60-64$ & 72.7 & 3.1 & 73.7 & 4.5 & 75.2 & 6.1 \\
$65-69$ & 79.0 & 3.1 & 79.6 & 4.5 & 80.4 & 6.1 \\
\hline
\end{tabular}

\subsubsection{Size of the Minimum Pension}

To measure the impact of changing the size of the Minimum Pension on employment and contribution decisions, we first increase it by $25 \%$ from $\$ 800,000$ pesos to $\$ 1,000,000$ pesos and then by $50 \%$ to $1,200,000$ pesos. In these policy experiments, we still required 80 quarters of contributions to be eligible to get the minimum pension.

Table 12 presents the effect of changing the size of the minimum pension on the accumulated quarters of work. Work in the covered sector increases when the size of the minimum pension is higher, especially for young men. By ages 33-39, an individual has accumulated 2.8 more quarters of work in the covered sector when the minimum pension is $25 \%$ higher and 7.9 more quarters when the minimum pension is $50 \%$ higher. Work in the uncovered sector decreases by a small amount. 
Table 12: Accumulated Quarters of Work in the Covered and Uncovered Sectors and Quarters not Working

\begin{tabular}{|c|c|c|c|c|c|c|c|c|c|}
\hline \multirow{3}{*}{$\begin{array}{l}\text { Size MPG } \\
\text { in pesos } \\
\text { Age Group }\end{array}$} & \multicolumn{3}{|c|}{$\$ 800,000$} & \multicolumn{3}{|c|}{$\$ 1,000,000$} & \multicolumn{3}{|c|}{$\$ 1,200,000$} \\
\hline & \multicolumn{3}{|c|}{ Baseline } & \multirow[b]{2}{*}{ Cov } & \multirow[b]{2}{*}{ Unc } & \multirow[b]{2}{*}{ NoW } & \multirow[b]{2}{*}{ Cov } & \multirow[b]{2}{*}{ Unc } & \multirow[b]{2}{*}{ NoW } \\
\hline & Cov & Unc & NoW & & & & & & \\
\hline $18-25$ & 3.9 & 6.5 & 5.2 & 4.7 & 6.5 & 4.4 & 6.3 & 6.5 & 2.8 \\
\hline $26-32$ & 14.7 & 18.2 & 8.5 & 16.6 & 17.5 & 7.3 & 20.1 & 16.7 & 4.5 \\
\hline 33-39 & 27.9 & 31.0 & 10.2 & 30.7 & 29.7 & 8.8 & 35.8 & 27.6 & 5.6 \\
\hline $40-44$ & 39.3 & 42.1 & 11.7 & 42.6 & 40.3 & 10.2 & 48.8 & 37.4 & 6.9 \\
\hline $45-49$ & 48.6 & 51.1 & 13.4 & 52.1 & 49.1 & 11.9 & 58.8 & 45.9 & 8.4 \\
\hline $50-54$ & 57.3 & 59.9 & 15.9 & 60.9 & 57.9 & 14.4 & 67.7 & 54.6 & 10.8 \\
\hline 55-59 & 65.4 & 68.5 & 19.3 & 68.8 & 66.6 & 17.7 & 75.6 & 63.4 & 14.2 \\
\hline $60-64$ & 72.7 & 76.8 & 23.6 & 76.1 & 75.0 & 22.1 & 82.6 & 71.9 & 18.5 \\
\hline $65-69$ & 79.0 & 84.0 & 30.1 & 81.9 & 81.8 & 29.4 & 87.9 & 78.2 & 27.1 \\
\hline
\end{tabular}

The accumulated quarters of contributions in the uncovered sector increase steadily for young individuals as observed in Table 13. At ages 33-39 a worker accumulates 4.6 more quarters of contributions when the size of the minimum pension increases $25 \%$ and accumulates 13.7 more quarters of contributions when the minimum pension increased by $50 \%$. In the last case, the accumulation of contributions is almost 5 times higher than in the baseline. 
Table 13: Accumulated Quarters of Contributions in the Covered and Uncovered Sectors

\begin{tabular}{|c|c|c|c|c|c|c|}
\hline \multirow{3}{*}{$\begin{array}{c}\text { Size of the Minimum } \\
\text { Pension in pesos } \\
\text { Age Group }\end{array}$} & \multicolumn{2}{|c|}{$\$ 800,000$} & \multicolumn{2}{|c|}{$\$ 1,000,000$} & \multicolumn{2}{|c|}{$\$ 1,200,000$} \\
\hline & \multicolumn{2}{|c|}{ Baseline } & & & & \\
\hline & Cov & Uncov & Cov & Uncov & Cov & Uncov \\
\hline $18-25$ & 3.9 & 1.0 & 4.7 & 2.3 & 6.3 & 4.4 \\
\hline $26-32$ & 14.7 & 2.3 & 16.6 & 5.5 & 20.1 & 11.1 \\
\hline $33-39$ & 27.9 & 2.9 & 30.7 & 7.5 & 35.8 & 16.6 \\
\hline $40-44$ & 39.3 & 3.1 & 42.6 & 8.3 & 48.8 & 19.8 \\
\hline $45-49$ & 48.6 & 3.1 & 52.1 & 8.6 & 58.8 & 21.9 \\
\hline $50-54$ & 57.3 & 3.1 & 60.9 & 8.6 & 67.7 & 21.9 \\
\hline $55-59$ & 65.4 & 3.1 & 68.8 & 8.6 & 75.6 & 21.9 \\
\hline $60-64$ & 72.7 & 3.1 & 76.1 & 8.6 & 82.6 & 21.9 \\
\hline $65-69$ & 79.0 & 3.1 & 81.9 & 8.6 & 87.9 & 22.0 \\
\hline
\end{tabular}

\subsection{Commissions}

In addition to the $10 \%$ of the taxable income that members pay as monthly contributions, they have to pay for health insurance and commissions, where the level of the commissions is set by each AFP. Currently the approximated average percentage commission is $2.5 \%$ of taxable income. From that $2.5 \%$, 0.85 percentage points are used to finance the disability and survivorship insurance, and the other 1.65 percentage points cover the AFPs' administrative costs and profits.

In the 1980s, the level of the percentage commission was around $3.5 \%$. It decreased subsequently until it reached around $2.5 \%$ in 2004. People in Chile often complain about the high commissions charged by the AFPs. For this reason, when the president Michelle Bachelet appointed a commission of experts to study the possible reforms to the pension system, one of the 
points of discussion related to lowering the administrative fees. According to the reforms to the pension system that the Congress approved at the beginning of 2008, new AFP members would also automatically be assigned to the AFP that charges the lowest fees, in an effort to increase the economic competitiveness among AFPs.

To assess the impact of changing commissions on employment and contributions, we simulate the effect of lowering the commission from $2.5 \%$ to $2.0 \%$ and then to $1.5 \%$. As can be observed in Table 14 the effect on work decisions of changes in commissions is very small. There is a positive effect on work in the covered sector, but even decreasing fees by $1 \%$ increases the accumulated quarters of covered work by less than one quarter. The effect in the uncovered sector is negative but of the same magnitude as that in the covered sector.

Table 14: Accumulated Quarters of Work in the Covered and Uncovered Sectors and Quarters not Working

\begin{tabular}{|c|c|c|c|c|c|c|c|c|c|}
\hline \multirow{2}{*}{$\begin{array}{l}\text { Commission } \\
\text { Age Group }\end{array}$} & \multicolumn{3}{|c|}{$2.5 \%$} & \multicolumn{3}{|c|}{$2.0 \%$} & \multicolumn{3}{|c|}{$1.5 \%$} \\
\hline & Cov & Unc & NoW & Cov & Unc & NoW & Cov & Unc & NoW \\
\hline $18-25$ & 3.9 & 6.5 & 5.2 & 4.0 & 6.5 & 5.1 & 4.0 & 6.5 & 5.1 \\
\hline $26-32$ & 14.7 & 18.2 & 8.5 & 14.7 & 18.1 & 8.5 & 14.8 & 18.1 & 8.5 \\
\hline 33-39 & 27.9 & 31.0 & 10.2 & 28.1 & 30.9 & 10.2 & 28.2 & 30.7 & 10.1 \\
\hline $40-44$ & 39.3 & 42.1 & 11.7 & 39.6 & 41.8 & 11.7 & 39.8 & 41.6 & 11.7 \\
\hline $45-49$ & 48.6 & 51.1 & 13.4 & 48.9 & 50.8 & 13.4 & 49.2 & 50.5 & 13.4 \\
\hline $50-54$ & 57.3 & 59.9 & 15.9 & 57.7 & 59.6 & 15.9 & 58.0 & 59.2 & 15.8 \\
\hline $55-59$ & 65.4 & 68.5 & 19.3 & 65.7 & 68.1 & 19.2 & 66.1 & 67.8 & 19.2 \\
\hline $60-64$ & 72.7 & 76.8 & 23.6 & 73.1 & 76.4 & 23.5 & 73.5 & 76.0 & 23.5 \\
\hline $65-69$ & 79.0 & 84.0 & 30.1 & 79.4 & 83.6 & 30.1 & 79.8 & 83.2 & 30.1 \\
\hline
\end{tabular}

As Table 15 shows that lowering the percentage commission has a very 
small positive effect on accumulated contributions. Although small, that effect on contributions in the uncovered sector is higher for young individuals when the commission is decreased from $2.5 \%$ to $1.5 \%$.

\begin{tabular}{|c|c|c|c|c|c|c|}
\hline \multirow[t]{2}{*}{ Percentage Commission } & \multicolumn{2}{|c|}{$\begin{array}{c}2.5 \% \\
\text { Baseline }\end{array}$} & \multicolumn{2}{|c|}{$2.0 \%$} & \multicolumn{2}{|c|}{$1.5 \%$} \\
\hline & Cov & Uncov & Cov & Uncov & Cov & Uncov \\
\hline $18-25$ & 3.9 & 1.0 & 4.0 & 1.1 & 4.0 & 1.7 \\
\hline $26-32$ & 14.7 & 2.3 & 14.7 & 2.5 & 14.8 & 2.6 \\
\hline 33-39 & 27.9 & 2.9 & 28.1 & 3.1 & 28.2 & 3.4 \\
\hline $40-44$ & 39.3 & 3.1 & 39.6 & 3.3 & 39.8 & 3.6 \\
\hline $45-49$ & 48.6 & 3.1 & 48.9 & 3.4 & 49.2 & 3.7 \\
\hline $50-54$ & 57.3 & 3.1 & 57.7 & 3.4 & 58.0 & 3.7 \\
\hline $55-59$ & 65.4 & 3.1 & 65.7 & 3.4 & 66.1 & 3.7 \\
\hline $60-64$ & 72.7 & 3.1 & 73.1 & 3.4 & 73.5 & 3.7 \\
\hline $65-69$ & 79.0 & 3.1 & 79.4 & 3.4 & 79.8 & 3.7 \\
\hline
\end{tabular}

\section{Conclusions}

Many pay-as-you-go pension systems are facing impending insolvency and transitioning to a fully funded pension system is one policy option. The Chilean Pension System has received much attention from researchers and policy makers because Chile was the first country that switched from a payas-you-go pension system to a private one based on individual capitalization. In the new system, contributions are deposited in individual accounts that are managed by the Pension Fund Managers (AFPs). The AFP system has come under some criticism, because more than half of the workforce is not currently contributing, especially the self-employed for whom contribution 
is voluntary and younger workers who tend to stay at home or work in the uncovered sector. The AFP system adopted several recent reforms that are designed to increase coverage rates and extend the state safety net.

We use a dynamic behavioral model of individual employment and contribution decisions to measure how individuals change their work and contribution decisions in response to changes in pension system characteristics. This model takes into account that contributions are mandatory in the covered sector but voluntary in the uncovered sector. We conduct two kinds of policy experiments regarding the Minimum Pension: 1) lower the number of quarters of contributions required to obtain the minimum pension guaranteed by the State and 2) increase the size of the minimum pension. These changes are similar to those reforms already approved by the Chilean Congress in January 2008.

For those individuals age 18-40, when the required number of quarters of contributions is decreased by $25 \%$, the accumulated number of quarters of work in the covered sector increases between 3 and $5 \%$ and the accumulated quarters of contributions increase between 30 and 40\%. Moreover, when that required number is decreased by $50 \%$, covered work increases between 6 and $10 \%$ and accumulated contributions paid while in the uncovered sector increase between 70 and $85 \%$. The effect on contributions while in the covered sector is the same as that on covered work because it is mandatory to contribute there. Thus, decisions to work in the covered sector are sensitive to the minimum requirements for a minimum pension.

With respect to changing the size of the minimum pension we find that when the size of the minimum pension is increased by $25 \%$, the accumulated 
quarters of work in the covered sector increases between 10 and $20 \%$ and the accumulated quarters of contributions in the uncovered sector increases by more than $100 \%$. The impact of increasing the size of the minimum pension by $50 \%$ is even higher. Accumulated quarters of work in the covered sector increases between 30 and $60 \%$ and accumulated quarters of contribution in the uncovered sector increase by around 4 times.

Two of the main goals of reforming the Chilean Individual Account Pension System were to increase contribution in the informal sector and to encourage labor market participation of young people. According to the results of the policy experiments, both reducing the quarters of contributions required to get the minimum pension and increasing the size of the minimum pension would be expected to have a significant positive effect both on work in the covered sector and on contributions in the uncovered sector.

\section{Bibliography}

Arenas de Mesa, A., Jere Behrman, and David Bravo (2004), "Characteristics of and Determinants of the Density of Contributions in a Private Social Security System", MRRC, University of Michigan, working paper.

Arenas de Mesa, A., David Bravo, Jere R. Behrman, Olivia S. Mitchell, and Petra E. Todd with assistance from Andrés Otero, Jeremy Skog, Javiera Vásquez, and Viviana Vélez Grajales (2006), "The Chilean Pension Reform Turns 25: Lessons from the Social Protection Survey", University of Pennsylvania, mimeo. 
Arenas de Mesa, and Carmelo Mesa-Lago (2006), "The Structural Pension Reform in Chile: Effects, Comparisons with other Latin American Reforms and Lessons", Oxford Review of Economic Policy, Vol. 22, No. 1.

Bellman, Richard (1957), "Dynamic Programming", Princeton Univ. Press, Princeton, NJ.

Edwards, Alejandra and Estelle James (2006), "Crowd-out, Adverse Selection and Information in Annuity Markets: Evidence from a New Retrospective Data Set in Chile", MRRC, University of Michigan, working paper.

French Eric (2005), "The Effects of Health, Wealth, and Wages on Labour Supply and Retirement Behaviour", Review of Economic Studies, 72, 395427.

Gustman, A. and Thomas Steinmeier (1986), "A Structural Retirement Model", Econometrica, Vol. 54, No. 3, 555-584.

Jiménez-Martín Sergi, and Alfonso R. Sánchez Martín (2007), "An Evaluation of the Life Cycle Effects of Minimum Pensions on Retirement Behavior", Journal of Applied Econometrics, 22: 923-950.

Lumsdaine, Robin L. and Olivia Mitchell (1999), "New Developments in the Economic Analysis of Retirement", Handbook of Labor Economics, Volume 3, Edited by O. Ashenfelter and D. Card. 
Keane, Michael and Kenneth Wolpin (1994), "The Solution and Estimation of Discrete Choice Dynamic Programming Models by Simulation and Interpolation: Monte Carlo Evidence", The Review of Economics and Statistics, volume 76 , no. 4, 648-672.

Keane, Michael and Kenneth Wolpin (1997), "The Career Decisions of Young Men", Journal of Political Economy, volume 105, no. 3, 473-522.

Ministerio del Trabajo y Previsión Social, Gobierno de Chile, "Manual Informativo. Síntesis de los Conceptos Fundamentales", April 2008.

Rust, J. and Christopher Phelan (1997), "How Social Security and Medicare Affect Retirement Behavior in a World of Incomplete Markets", Econometrica, Vol. 65, No. 4, 781-831.

Stock, J. and David Wise (1990), "Pensions, the Option Value of Work, and Retirement", Econometrica, Vol. 58, No. 5, 1151-1180.

Superintendency of Pension Fund Administrators, "The Chilean Pension System", Fourth Edition, Santiago-Chile, 2003.

Todd Petra E., and Kenneth I. Wolpin, "Ex Ante Evaluation of Social Programs", PIER Working Paper 06-022, University of Pennsylvania, May 2006. Valdés Salvador (2007), "Pensión Solidaria: Ventajas, Defectos y Propues- 
tas", Instituto de Economía, Pontificia Universidad Católica de Chile, Dirección de Asuntos Públicos.

Van der Klaauw, W. and Kenneth Wolpin (2005), "Social Security and the Retirement and Savings Behavior of Low Income Households", University of Pennsylvania, mimeo.

Velez-Grajales Viviana (2008), "Reforms to an Individual Account Pension System and their Effects on Work and Contribution Decisions: The Case of Chile", Working paper, University of Pennsylvania.

\section{Appendix A: Functional Forms}

\section{Utility Function}

$$
\begin{aligned}
U_{a}= & \frac{\sum_{a=1}^{2} I(\text { type }=h) \theta_{1}^{h}}{C_{h=1}^{2} I(t y p e=h) \theta_{1}^{h}}\left[1+\exp \left(\theta_{2} l_{a}+\theta_{3} M_{a}+\theta_{4} \varepsilon_{a}^{C}\right)\right]+\theta_{5} l_{a}+\theta_{6} l_{a}(25-a) I_{(a \leq 25)}+ \\
& \theta_{7} l_{a}\left(1-M_{a}\right)+\theta_{8} l_{a} H_{a}+\theta_{9} s_{a}^{u}\left(1+0.15(25-a) I_{(a \leq 25)}\right)+\theta_{10} \varepsilon_{a}^{l}
\end{aligned}
$$

\section{Wage Function in Covered Sector}

$\ln \left(w_{a}^{c}\right)=\sum_{h=1}^{2} I($ type $=h) \gamma_{1}^{h}+\gamma_{2} E+\gamma_{3} G+\gamma_{4} T_{a}^{c}+\gamma_{5}\left(T_{a}^{c}\right)^{2}+\gamma_{6} T_{a}^{u}+\gamma_{7}\left(T_{a}^{u}\right)^{2}+\gamma_{8} \varepsilon_{a}^{c}$ 


\section{Wage Function in Uncovered Sector}

$\ln \left(w_{a}^{u}\right)=\sum_{h=1}^{2} I($ type $=h) \xi_{1}^{h}+\xi_{2} E+\xi_{3} G+\xi_{4} T_{a}^{c}+\xi_{5}\left(T_{a}^{c}\right)^{2}+\xi_{6} T_{a}^{u}+\xi_{7}\left(T_{a}^{u}\right)^{2}+\xi_{8} \varepsilon_{a}^{u}$

Probability of Getting Married $\left(M_{a}=1\right)$

$$
\pi_{a}^{M}=\sum_{h=1}^{2} I(\text { type }=h) \alpha_{1}^{h}+\alpha_{2} a+\alpha_{3} a^{2}+\alpha_{4} E+\alpha_{5} E^{2}
$$

Probability of Being in Bad Health $\left(H_{a}=1\right)$

$$
\pi_{a}^{H}=\sum_{h=1}^{2} I(\text { type }=h) \beta_{1}^{h}+\beta_{2} a+\beta_{3} a^{2}+\beta_{4} E+\beta_{5} E^{2}
$$

\section{Appendix B: Estimates}


Table 16: Estimates: Part 1

Utility function

Mean

$\theta_{1}^{1}=$ CRRA parameter type 1

0.5

$\theta_{1}^{2}=\mathrm{CRRA}$ parameter type 2

0.5

$\theta_{2}=$ Consumption*leisure

0.2

$\theta_{3}=$ Consumption $*$ bad health

$-0.08$

$\theta_{4}=$ Shock to consumption

0.1

$\theta_{5}=$ Leisure

70.0

$\theta_{6}=$ Leisure for young

70.0

$\theta_{7}=$ Leisure ${ }^{*}$ single

574.1

$\theta_{8}=$ Leisure $^{*}$ bad health

400.0

$\theta_{9}=$ Shock to leisure

0.1

$\theta_{10}=$ Non-pecuniary term for work in the uncovered sector

0.3

Wage Offer in the Covered Sector

$\gamma_{1}^{1}=$ Constant type 1

Mean

$\gamma_{1}^{2}=$ Constant type 2

12.8

12.3

$\gamma_{2}=$ Years of education

0.08

$\gamma_{3}=$ Region of residence

0.07

$\gamma_{4}=$ Years of work exp. in the covered sector

0.033

$\gamma_{5}=$ Years of work exp. in the covered sector squared

$-0.00023$

$\gamma_{6}=$ Years of work exp. in the uncovered sector

0.0028

$\gamma_{7}=$ Years of work exp. in the uncovered sector squared

$-0.000025$

\section{Wage Offer in the Uncovered Sector}

$\xi_{1}^{1}=$ Constant type 1

Mean

$\xi_{1}^{2}=$ Constant type 2

11.7

11.8

$\xi_{2}=$ Years of education

0.08

$\xi_{3}=$ Region of residence

0.1

$\xi_{4}=$ Years of work exp. in the covered sector

0.0001

$\xi_{5}=$ Years of work exp. in the covered sector squared

$-0.00001$

$\xi_{6}=$ Years of work exp. in the uncovered sector

0.024

$\xi_{7}=$ Years of work exp. in the uncovered sector squared

$-0.00014$ 
Table 17: Estimates: Part 2

\section{Probability of getting married}

$\alpha_{1}^{1}=$ Constant type 1

$\alpha_{1}^{2}=$ Constant type 2

$\alpha_{2}=$ Age

$\alpha_{3}=$ Age squared

$\alpha_{4}=$ Years of education

$\alpha_{5}=$ Years of education squared
Mean

$-15.2$

$-15.3$

0.9

$-0.018$

0.1

$-0.007$

Mean

$-8.3$

$-8.2$

0.1

0.000001

$-0.9$

0.006

Probability of being type 1

Mean

Constant

$-1.95$

Age when finished studying

0.02

Years of education

0.11

Region

0.18

Married

0.01

Bad health

0.01

\section{Returns}

Mean

Mean

0.11

Variance-Covariance matrix for the shocks

Variance preference for consumption

Mean

Variance preference for leisure

1.1

Variance covered sector wage offer

1.1

Variance uncovered sector wage offer

0.7

Variance returns

1.5

0.005 